\title{
Increased methylation of human papillomavirus type 16 DNA is associated with the severity of cervical lesions in infected females from northeast China
}

\author{
WEI WANG ${ }^{1}$, ZHENGRONG SUN $^{2}$, JIANHUA LIU $^{1,3}$, GUILI WANG $^{1}$, \\ ZHITAO LU ${ }^{1}$, WEIQIANG ZHOU ${ }^{1}$, TE QI ${ }^{1}$ and QIANG RUAN ${ }^{1}$ \\ ${ }^{1}$ Virus Laboratory; ${ }^{2}$ BioBank; ${ }^{3}$ Department of Clinical Laboratories, The Affiliated Shengjing Hospital, \\ China Medical University, Shenyang, Liaoning 110004, P.R. China
}

Received August 26, 2015; Accepted January 26, 2017

DOI: $10.3892 / \mathrm{ol} .2017 .5903$

\begin{abstract}
Hypermethylation of the cytosine-phosphate-guanine $(\mathrm{CpG})$ sites located at the 3'-major capsid protein L1 ( $\left.3^{\prime} \mathrm{L} 1\right)$ and the long control region (LCR) of the human papillomavirus (HPV) genome may be associated with the progression of cervical cancer (CC). However, the methylation status of the LCR of HPV type 16 DNA remains to be elucidated in an infected Chinese population. The aim of the present study was to investigate the association between methylation of the HPV $16 \mathrm{~L} 1$ gene and LCR, and the severity of cervical lesions in infected female patients. Therefore, bisulfite modification, polymerase chain reaction amplification and sequencing were used to analyze $122 \mathrm{HPV}$ 16-positive clinical cervical swabs obtained from patients in northeastern China. The proportion of methylated samples at each of the $7 \mathrm{CpG}$ sites within the $3^{\prime}-\mathrm{L} 1 / 5^{\prime}-\mathrm{LCR}$ and $5 \mathrm{CpG}$ sites within the promoter region was significantly increased in patients with $\mathrm{CC}$, compared with that observed in high-grade squamous intraepithelial lesions (HSIL) and normal tissue/low-grade intraepithelial lesions (LSIL) $\left(\chi^{2}\right.$ test, $\left.\mathrm{P}<0.01\right)$. The mean methylation frequencies of the $\mathrm{CpG}$ sites 7,089 and 7,143 exhibited an area under the curve value of 0.822 [95\% confidence interval $(\mathrm{CI})=0.733-0.911]$ for distinguishing $\mathrm{CC}$ from other lesions, 0.787 (95\% CI=0.700-0.874) for distinguishing normal/LSIL from HSIL and CC, and 0.763 (95\% CI=0.652-0.874) for distinguishing $\mathrm{CC}$ from HSIL. These results suggest that the
\end{abstract}

Correspondence to: Professor Zhengrong Sun, BioBank, The Affiliated Shengjing Hospital, China Medical University, 36 Sanhao Street, Heping, Shenyang, Liaoning 110004, P.R. China

E-mail:sunzr@sj-hospital.org

Professor Qiang Ruan, Virus Laboratory, The Affiliated Shengjing Hospital, China Medical University, 36 Sanhao Street, Heping, Shenyang, Liaoning 110004, P.R. China

E-mail: ruanq@sj-hospital.org

Key words: human papillomavirus type 16, 3'-major capsid protein L1 gene, long control region, methylation, cervical lesion methylation of $\mathrm{CpG}$ sites within the HPV 16 3'-L1 and LCR region is correlated with the severity of cervical lesions. Quantification of HPV DNA methylation in the L1 gene and promoter region appears to provide a promising novel marker for distinguishing between normal tissue/LSIL, HSIL and CC in a Chinese population.

\section{Introduction}

Cervical cancer (CC) is one of the most common types of carcinoma in females worldwide, and is frequently associated with high-risk human papillomavirus type 16 (HPV 16) infection (1-3). HPV 16 infections are common; however, limited progress has been made towards the elucidation of the mechanisms underlying the formation of precursor lesions, cervical intraepithelial neoplasia grade 2/3 (CIN2/3) and $\mathrm{CC}$ itself $(4,5)$. Malignancy is a rare outcome involving complex interactions between the host, the environment and the virus $(6,7)$. Initially, cytology-based screening programs were successful in reducing the incidence and mortality rates of invasive CC in developed countries (7-9). Due to the limitations of the screening programs, including suboptimal sensitivity for CIN $2 / 3$ and cancer and limited uptake, it is necessary to develop a novel screening method. In recent years, screening through the detection of HPV 16 DNA has emerged as a method of identifying cervical lesions (10). However, this method is unable to distinguish between those infections that may progress to cancer and self-limited infections $(9,10)$. Quantitative evaluation of HPV DNA methylation may, therefore, be a simple method of triaging the severity levels of cervical lesions and overcome the limitations of the current screening programs.

DNA methylation is the process of the addition of a methyl group to the 5'position of cytosine, which often occurs at the position of cytosine-phosphate-guanine $(\mathrm{CpG})$ dinucleotides (11). As a major epigenetic modification mechanism, DNA methylation is able to regulate gene expression (12). Hypermethylation of $\mathrm{CpG}$ sites in certain genes has been recognized as a frequent early event in the pathogenesis of numerous forms of cancer, including CC (13). The quantification of HPV DNA methylation may be of value in the early 
detection of precursors of certain types of cancer, providing reassurance to HPV-infected patients whom, to avoid unnecessary overtreatment, are candidates for less-frequent screening.

The L1 gene is an HPV 16 late gene that encodes the major capsid protein (3). Previous studies have demonstrated that methylation is highly prevalent in the L1 gene of HPV 16 , the products of which are not required for neoplastic processes $(11,14,15)$. As the primary control region of the virus, the long control region (LCR) contains numerous regulatory elements that are involved in viral DNA replication and transcription, including promoters and enhancers $(12,13)$. A previous study revealed an association between LCR variation and an increased risk of developing CIN2/3 in an HPV 16-infected population of female Chinese patients (16). It has been predicted that variations in the LCR are able to alter specific transcription factor binding sites (16). To the best of our knowledge, the methylation status of HPV 16 in the L1 and the LCR has not yet been investigated in female patients living in northeastern China. The current study aimed to examine the methylation status of HPV 16 in a portion of the L1 gene and the LCR in a collection of clinical tissue samples, and to determine the association between HPV 16 methylation and the cervical disease grade of infected patients.

\section{Materials and methods}

Samples and DNA preparations. Following routine diagnoses using flow-through hybridization (Hybribio Ltd, Hong Kong, China), HPV 16-positive clinical cervical swabs between April 2014 and May 2015 were obtained from 180 female patients (18-70 years old) admitted to The Affiliated Shengjing Hospital, China Medical University (Shenyang, China) for use in the present retrospective study. According to the histological evaluation of fresh tissue specimens from the female patients, 122 clinical tissue samples were selected between April 2014 and May 2015, including 42 cases of normal and low-grade squamous intraepithelial lesion (normal tissue/LSIL), 40 cases of high-grade squamous intraepithelial lesion (HSIL) and 40 cases of cervical cancer (CC). A total of 58 samples were not included due to indefinite diagnosis and require clinical examination). Liquid-based cytology (LBC) samples were processed according to the manufacturer's instructions and stained using the Papanicolaou method. The liquid-based specimens were processed with the Cytyc T2000 Processor (Cytyc, Inc., Marlborough, MA, USA), and final cytologic diagnoses were issued using the Bethesda System (17). All cytology testing was performed by 2 independent pathologists who were blinded to the HPV detection results. The present study was approved by the ethics committee of the Affiliated Shengjing Hospital.

DNA was extracted and purified from a $200 \mu 1$ aliquot of cervical swab suspended in specimen transport medium, using a QIAamp DNA Mini kit (Qiagen, Inc., Valencia, CA, USA), according to the manufacturer's protocol. The extracted DNA was suspended in $50 \mu \mathrm{l}$ buffer AE [10 mM Tris-HCl, $0.5 \mathrm{mM}$ EDTA (pH 9.0)].

Bisulfite modification. For each cervical swab sample, the extracted DNA was treated with sodium bisulfite using the EZ DNA Methylation-Gold ${ }^{\mathrm{TM}}$ kit (Zymo Research, Corp, Irvine,
CA, USA), according to the recommended protocol. Briefly, 200-500 ng of each DNA sample was mixed with $130 \mu \mathrm{l}$ CT Conversion Reagent (900 $\mu \mathrm{l}$ water, $300 \mu \mathrm{l}$ M-Dilution buffer and $50 \mu \mathrm{l} \mathrm{M}$-dissolving buffer) and incubated at $98^{\circ} \mathrm{C}$ for $10 \mathrm{~min}$ and $64^{\circ} \mathrm{C}$ for $2.5 \mathrm{~h}$. Subsequently, the mixture and $600 \mu 1 \mathrm{M}$-Binding Buffer were added to a Zymo-Spin ${ }^{\mathrm{TM}}$ IC Column (Zymo Research). Following centrifugation (1,500 x $g$ at $25^{\circ} \mathrm{C}$ for $1 \mathrm{~min}$ ), washing with $100 \mathrm{ml} \mathrm{M}$-wash buffer and desulfonation with $100 \mathrm{ml}$ M-desulfonation buffer (incubation for $20 \mathrm{~min}$ at $25^{\circ} \mathrm{C}$, centrifugation $\left(1,500 \times \mathrm{g}\right.$ at $25^{\circ} \mathrm{C}$ for $\left.1 \mathrm{~min}\right)$ and washing with $100 \mathrm{ml} \mathrm{M}$-wash buffer), the converted DNA was eluted in $10 \mu \mathrm{l} \mathrm{TE}$ buffer (10 mM Tris-HCl; 1 mM EDTA; $\mathrm{pH}$ 8.0) and the recovered DNA was stored at $-20^{\circ} \mathrm{C}$.

Amplification of bisulfite-treated DNA, TA cloning and sequencing. Certain regions of the HPV 16 genome were analyzed by amplification of bisulfite-treated DNA, TA cloning and sequencing, including the 3 'end of the L1 gene (3'-L1) and the full length of the LCR. As sections of the DNA may have been degraded into small fragments during the bisulfite treatment, the analyzed DNA segment was divided into three amplicons (14), including the 3'-L1/5'-LCR, enhancer and promoter regions. A total of three pairs of primers were designed using the MethPrimer Design program (MethPrimer 2.0; Li Lab, Beijing, China) (18) and are listed in Table I.

Polymerase chain reaction was performed with $1 \mu \mathrm{l}$ bisulfite-modified DNA, $10 \mathrm{mM}$ dNTPs, $0.5 \mathrm{mM}$ primers, $50 \mathrm{mM}$ $\mathrm{MgCl}_{2}, 10 X$ PCR buffer (200 mM Tris- $\mathrm{HCl}$ (pH 8.4), $500 \mathrm{mM}$ $\mathrm{KCl}$ ) and Platinum ${ }^{\circledR}$ Taq DNA polymerase (Invitrogen; Thermo Fisher Scientific, Inc., Waltham, MA, USA) for a total reaction volume of $50 \mu \mathrm{l}$. The PCR thermocycling conditions were as follows: $94^{\circ} \mathrm{C}$ for $9 \mathrm{~min}$, followed by 44 cycles of $94^{\circ} \mathrm{C}$ for $30 \mathrm{sec}, 5^{\circ} \mathrm{C}$ for $30 \mathrm{sec}$ and $72^{\circ} \mathrm{C}$ for $45 \mathrm{sec}$, with a final extension at $72^{\circ} \mathrm{C}$ for $10 \mathrm{~min}$. Amplicon presence was confirmed using $1 \%$ agarose gel electrophoresis with ethidium bromide and the DNA samples were purified using the Wizard ${ }^{\circledR}$ SV Gel and PCR Clean-Up system (Promega Corporation, Madison, WI, USA). The purified PCR products were cloned into the $\mathrm{pCR}^{\mathrm{TM}}$ 2.1 vector using the Original TA Cloning ${ }^{\circledR}$ kit (Invitrogen; Thermo Fisher Scientific, Inc.), then conversion into E. coli (DH5 $\alpha$; Tiangen Biotech Co., Ltd., Beijing, China) and cultivated at $37^{\circ} \mathrm{C}$. Strains of E. coli DH5 $\alpha$ containing recombinant plasmid were inoculated into $5 \mathrm{ml} \mathrm{LB}$ liquid medium with $100 \mu \mathrm{g} / \mathrm{ml}$ Ampicillin and agitated overnight at $37^{\circ} \mathrm{C}$ for $12 \mathrm{~h}$. Subsequently, the plasmid was purified using Wizard Plus SV Minipreps DNA Purification System (Promega Corporation). A total of 5 clones of each DNA sample were selected randomly for determination of methylation at $\mathrm{CpG}$ sites. In brief, each clone selected was propagated for PCR and sequencing. The PCR reaction was amplified with a pair of primers: Forward, 5'-TGTAAAACGACGGCCAGT-3' and reverse, 5'-CAG GAAACAGCTATGACC-3'. The reaction was setup in a total volume of $20 \mu \mathrm{l}$ containing $10 \mathrm{mM}$ dNTPs, $0.2 \mathrm{mM}$ primers, 10X PCR $\left(\mathrm{Mg}^{2+}\right.$ plus) buffer and 0.8 unit Taq DNA polymerase (Takara Taq $^{\mathrm{TM}}$; Takara Bio, Inc., Otsu, Japan). Amplicon presence was confirmed using $1 \%$ agarose gel electrophoresis with ethidium bromide. The clones that were successful amplified were used for sequencing (Invitrogen, Beijing, China), and the results were subsequently analyzed by Bioedit version 4.8.10 (Department of Microbiology, North Carolina State 
Table I. Polymerase chain reaction primer sequences.

\begin{tabular}{lll}
\hline Genomic region & \multicolumn{1}{c}{ Primers } & CpG nt position \\
\hline 3'-L1 and 5'-LCR & F: 5'-TAGGATTGAAGGTTAAATTAAAATT-3' & $7,089^{\mathrm{a}}, 7,134^{\mathrm{a}}, 7,143^{\mathrm{a}}, 7,268$, \\
& R: 5'-AACACATTTTATACCAAAAAACA-3' & $7,426,7,452,7,458$ \\
Enhancer & F: 5'-TATGTTTTTTGGTATAAAATGTGTTTTT-3' & $7,532,7,550,7,673,7,679$, \\
& R: 5'-TAAATTAATTAAAACAAACCAAAAATATAT-3' & 7,691 \\
Promoter & F: 5'-TTTGTAAAATTGTATATGGGTGT-3' & $7,859^{\mathrm{b}}, 31,37,43,52,58$ \\
& R: 5'-TCCTAAAACATTACAATTCTCTTT-3' & \\
\hline
\end{tabular}

CpG sites located in the ${ }^{\mathrm{a}} 3$ '-L1 region and ${ }^{\mathrm{b}}$ replication origin. $\mathrm{CpG}$, cytosine-phosphate-guanine; Nt, nucleotide; F, forward; R, reverse; L1, late region 1; LCR, long control region.

University). The DNA samples were considered to be methylated at a certain $\mathrm{CpG}$ site if $\geq 1$ clone exhibited a methylated cytosine at this site (19). The methylation frequency of each CpG site in a particular DNA sample was calculated based on the ratio of methylated clones to the five detected clones.

Statistical analysis. The differences in the proportion of methylation in DNA samples from the various patient groups were analyzed using the $\chi^{2}$ test. Receiver operating characteristic (ROC) analysis was performed in order to examine the sensitivity and specificity of the methylation frequency of each $\mathrm{CpG}$ site for distinction between the various types of cervical lesion using the optimal threshold values and, therefore, determine the most informative methylation frequency for $\mathrm{CpG}$ sites. ROC analyses were performed for three groups, as follows: CC vs. normal tissue/LSIL and HSIL; CC and HSIL vs. normal tissue/LSIL; CC vs. HSIL. The significance of each combination of $\mathrm{CpG}$ sites was assessed by comparing the obtained area under the curve (AUC) values. ROC curves and AUC values were also calculated for the mean methylation frequency of the combination of $\mathrm{CpG}$ sites. All tests were two-tailed and $\mathrm{P}<0.05$ was considered to indicate a statistically significant difference.

\section{Results}

The clinical DNA specimens were sequenced effectively. A total of 122 clinical DNA specimens were examined in the present study. The methylation status of $\mathrm{CpG}$ sites in the 3'-L1/5'-LCR was detected in cervical swab samples from 30 patients with normal tissue/LSIL, 35 patients with HSIL and 35 patients with CC. DNA specimens from the enhancer region were successfully analyzed in tissue samples from 30 , 31 and 30 patients with normal tissue/LSIL, HSIL and CC, respectively. In the promoter region, the methylation status of the $\mathrm{CpG}$ sites was effectively analyzed in tissue samples from 37 patients with normal tissue/LSIL, 35 patients with HSIL and 37 patients with CC.

Methylation proportion observed in HPV 16 positive cervical swab samples. A total of $18 \mathrm{CpG}$ sites were scattered in the section of the genome studied. Among the $18 \mathrm{CpG}$ sites, 3 were located in the 3 '-L1 at nucleotide (nt) 7,089, 7,134 and 7,143, 4 were located in the 5'-LCR at nt 7,268, 7,426, 7,452 and 7,458 and5 were located in the enhancer region at nt 7,532, 7,550, 7,73, 7,679 and 7,691. In addition, $1 \mathrm{CpG}$ site was located in the replication origin at $\mathrm{nt} 7,859$, and 5 were identified in the promoter region at nt 31, 37, 43, 52 and 58. The mean methylation frequency at each $\mathrm{CpG}$ site in DNA samples obtained from the various patient groups is summarized in Fig. 1. The mean methylation proportion of the $18 \mathrm{CpG}$ sites of all the analyzed DNA samples was 25.04\% (453 methylated/1,809 analyzed CpG sites). The mean methylation proportion of the study DNA samples at individual $\mathrm{CpG}$ sites ranged from between 5.49 and $51.00 \%$. Overall, the methylation proportion of DNA samples at the $3 \mathrm{CpG}$ sites within the 3 '-L1 region and the 5 $\mathrm{CpG}$ sites in the promoter region was higher, compared with that observed in the 5'-LCR and enhancer regions.

Association between the methylation proportion at the studied CpG sites in HPV 16-positive DNA samples and the severity of cervical lesions in infected female patients. The mean methylation proportion at the $18 \mathrm{CpG}$ sites in DNA samples from patients with normal tissue/LSIL, HSI and CC was 8.42\% (49 methylated/582 analyzed CpG sites), 18.36\% (112 methylated/610 analyzed CpG sites) and 47.33\% (292 methylated/617 analyzed $\mathrm{CpG}$ sites), respectively ( $\chi^{2}$ test, $\mathrm{P}<0.001$; Table II). The methylation proportion of $\mathrm{CpG}$ sites within the studied regions was highest in cervical swab DNA samples from patients with $\mathrm{CC}$, and lowest in those from patients with normal tissue/LSIL (Fig. 1).

The proportion of $\mathrm{CpG}$ methylation at nt 7,089, 7,134, 7,143, 7,268, 7,426, 7,452, 7,458, 7,673, 31, 37, 43, 52 and 58 was highest in DNA samples from patients with $\mathrm{CC}$, followed by those from patients with HSIL, and were lowest in DNA samples from patients with normal tissue/LSIL $(\mathrm{P}<0.05$; Table II). The proportion of methylation in DNA samples from patients with normal tissue/LSIL and patients with CC in the origin of replication, at the $\mathrm{CpG}$ site 7,859 was $2.70 \%$ and $24.32 \%$, respectively $(\mathrm{P}<0.001)$.

As presented in Table II, the variation in the methylation proportion between cervical swab DNA samples from patients with normal tissue/LSIL and HSIL, normal tissue/LSIL and CC, and HSIL and CC at CpG sites 7,089 and 7,143 was significantly different $(\mathrm{P}<0.05$; Table II). No significant differences in the methylation proportion were identified between DNA samples from patients with normal tissue/LSIL and HSIL at the CpG sites 7,134, 7,268, 7,426, 7,452, 7,673, 7,859, 31, 37, 


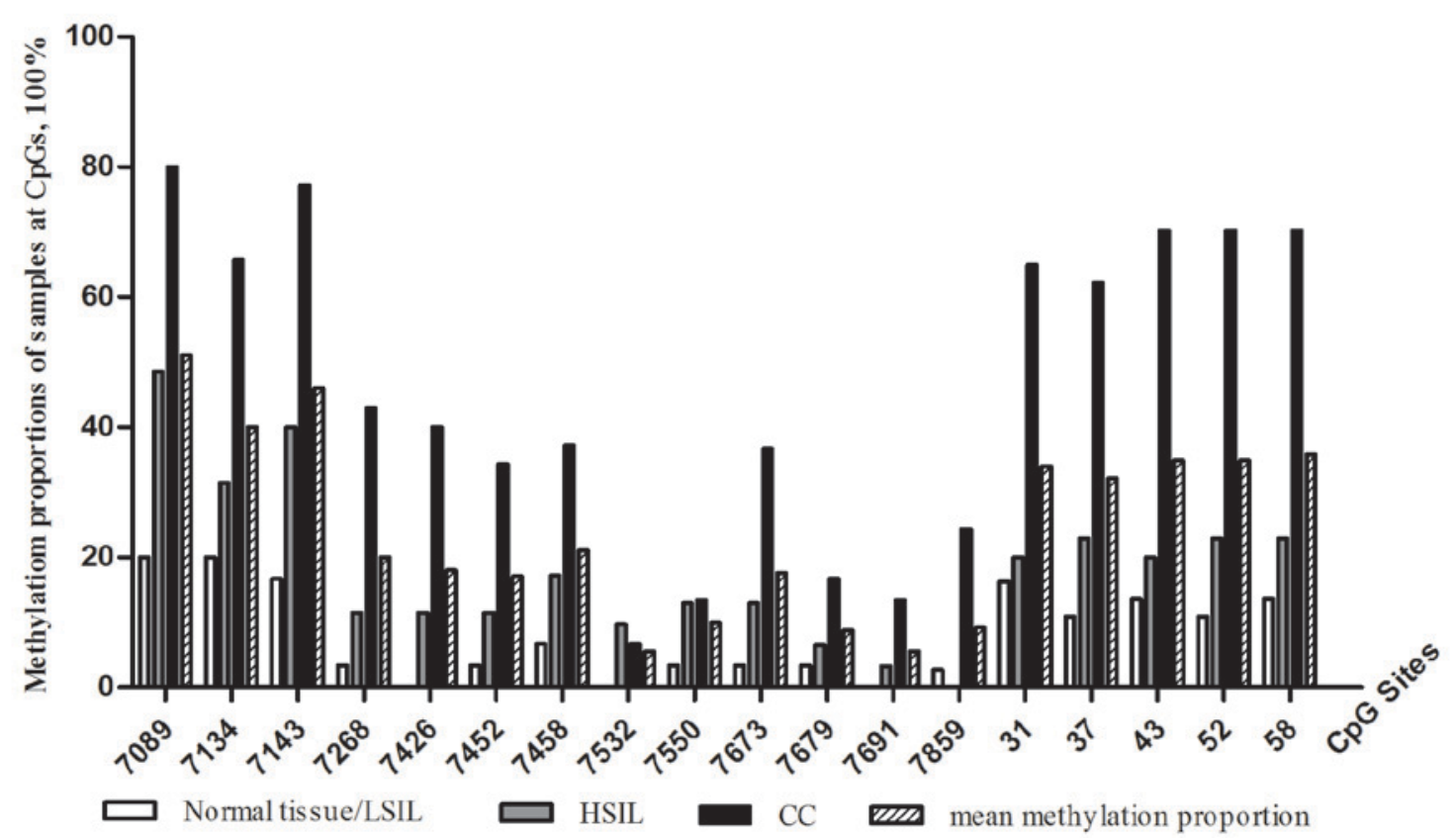

Figure 1. Methylation proportions at $18 \mathrm{CpG}$ sites within the HPV 16 genome in DNA samples from various cervical lesions, and the mean methylation proportion of all DNA samples at each CpG site. CpG, cytosine-phosphate-guanine; HPV, human papilloma virus; LSIL, low-grade intraepithelial lesions; HSIL, high-grade intraepithelial lesions; $\mathrm{CC}$, cervical cancer.

43, 52 and 58; however, significant differences were observed between patients with normal tissue/LSIL and patients with CC, HSIL and CC at these sites $(\mathrm{P}<0.05$; Table II). The difference in the proportion of methylation at $\mathrm{CpG}$ site 7,458 was significant only between DNA samples from patients with normal tissue/LSIL and CC ( $\mathrm{P}=0.004$; Table II).

Association between the methylation frequency of $\mathrm{Cp} G$ sites 7,089 and 7,143 and the severity of cervical lesions of infected female patients. In order to elucidate the association between the methylation frequency of $\mathrm{CpG}$ sites 7,089 and 7,143 (individually or in combination) and the severity of the cervical lesions in infected patients, ROC analysis was conducted. The results revealed that the methylation frequencies of the two $\mathrm{CpG}$ sites, individually or in combination, were able to differentiate between cervical swab DNA patients with CC and samples from patients with normal tissue/LSIL or HSIL (Fig. 2A). The AUC values for distinguishing CC from normal tissue/LSIL and HSIL were 0.782 (95\% CI, 0.683-0.881) for the methylation frequency of $\mathrm{CpG}$ site 7,089, and 0.796 (95\% CI, 0.697-0.895) for that of $\mathrm{CpG}$ site 7,143 (Table III). The AUCs values for distinguishing CC and HSIL from normal tissue/LSIL were 0.754 (95\% CI, 0.660-0.848) for the methylation frequency of $\mathrm{CpG}$ site 7,089, and 0.736 (95\% CI, 0.640-0.832) for that of CpG site 7,143. The AUC values were improved using a combination of the methylation frequencies of the two $\mathrm{CpG}$ sites, with an effective distinction between CC and normal tissue/LSIL and HSIL (77.1\% sensitivity, $73.8 \%$ specificity) obtained using the mean methylation frequency of $\mathrm{CpG}$ sites 7,089 and 7,134 (AUC=0.822; 95\% CI, 0.733-0.911) when a $15 \%$ methylation frequency was used as a threshold (Fig. 2A and Table III). CC and HSIL were distinguishable from normal tissue/LSIL with $72.9 \%$ sensitivity and $73.3 \%$ specificity, using the mean methylation frequencies of the $\mathrm{CpG}$ sites 7,089 and 7,134 (AUC=0.787; 95\% CI, 0.700-0.874) and a 5\% methylation frequency as a critical threshold (Fig. 2B and Table III). Concordant trends were observed when distinguishing CC from HSIL using a $15 \%$ methylation frequency as the threshold, which yielded $77.1 \%$ sensitivity and $62.9 \%$ specificity $(\mathrm{AUC}=0.763 ; 95 \% \mathrm{CI}$, 0.652-0.874; Fig. 2C; Table III).

\section{Discussion}

DNA methylation is an epigenetic mechanism that is able to inhibit gene expression directly by interfering with transcription factor binding, or indirectly by recruiting histone deacetylases through methyl-DNA-binding proteins $(20,21)$. Previous studies have demonstrated that DNA methylation is also an important method of regulating the expression of the HPV 16 gene by blocking certain transcription factor binding sites, and is associated with the presence of cervical lesions $(22,23)$. At present, it is acknowledged that HPV 16 exhibits varied methylation patterns in asymptomatic infection, or in low-grade lesions, high-grade lesions and CC, and that this mechanism primarily targets the late genes and the LCR (5). Hypermethylation of the CpG islands located at the 3'L1 gene and the LCR of the HPV genome may be associated with cancer progression; however, the methylation status of the region in HPV 16 DNA has yet to be elucidated in an infected Chinese population.

The present study examined the methylation status of 18 CpG sites encompassing the 3 ' end of the L1 gene and the LCR of the HPV 16 genome using bisulfite modification, cloning and sequencing. The $18 \mathrm{CpG}$ sites were located as follows: 3 in the 3 '-L1 at nt 7,089, 7,134 and 7,143; 4 in the 5'-LCR at nt 
$7,268,7,426,7,452$ and 7,458; 5 in the enhancer at nt 7,532, $7,550,7,673,7,679$ and 7,691; 1 in the replication origin at nt 7,$859 ; 5$ in the promoter at nt 31,37, 43, 52 and 58. Bisulfite modification is able to convert all unmethylated cytosines, but not methylated cytosines, to uracils (5). Whether bisulfite treatment was completed or not may be determined by the sequencing results of unmethylated cytosines in the study region. In the present study, all DNA samples were effectively treated with sodium bisulfite.

The results of the current study revealed that the three $\mathrm{CpG}$ sites in the 3'-L1 fragment at nt 7,089, 7,134 and 7,143 were hypermethylated, and the methylation proportions of cervical swab DNA samples from patients with normal tissue/LSIL, HSIL and CC at these three sites were significantly different. Although hypermethylation of the L1 region may provide an improved estimate of the methylation level of the virus (5), to the best of our knowledge, no studies have suggested that methylated L1 promotes the development of CC.

Methylation may be a host cell defense against HPV infection (6). During carcinogenesis, HPV DNA is integrated into the host genome (24-28), and the hypermethylation observed in patients with CC may result from a host defense mechanism that senses the integrated viral genome as foreign and targets it for epigenetic modification (19). In patients with normal tissue/LSIL, the L1 gene is unmethylated and expresses the capsid protein of the episomal form of the virus (5). As additional HPV DNA integrates into the host genome during the process of carcinogenesis (29), the L1 gene is methylated and translation is inhibited, which may reduce the expression of the capsid protein and trigger viral evasion of host immune control during HPV reproduction (30). Kalantari et al (5) revealed an increased methylation rate at the three $\mathrm{CpG}$ sites in the HPV $16 \mathrm{~L} 1$ region, occurring during the progression from LSIL/CIN1 to invasive cancer. This result is concordant with the data from the present study, which revealed that the methylation proportions at $\mathrm{CpG}$ sites 7,268, 7,426 and 7,452 in the 5'-LCR, between DNA samples from patients with normal tissue/LSIL and HSIL and CC, increased during the growth of cervical lesions. A similar association was observed in the three $\mathrm{CpG}$ sites in the $\mathrm{L} 1$ region, with the differences being statistically significant.

The promoter is controlled by the enhancer, the activity of which is retained in the enhancer core (20). Therefore, the promoter and the enhancer core are the crucial segments of the HPV 16 LCR. For the $\mathrm{CpG}$ sites in the enhancer and promoter regions, the methylation proportion was lowest in cervical swab DNA samples from patients with normal tissue/LSIL, and highest in those with CC. Previous studies have demonstrated that methylation is able to regulate gene expression as an epigenetic mechanism (31-33). Numerous transcription factor binding sites in the HPV 16 enhancer and promoter regions contain $\mathrm{CpG}$ sites (19). CpG sites at nt 7,532, 7,550 and 7,679 are in proximity to the activator protein 1 and nuclear factor I binding sites, the site at nt 31 is within the specificity protein 1 binding site; and those $\mathrm{CpG}$ sites at nt 37, 43, 52 and 58 are within the first twoE2 binding sites (19). Methylation of these $\mathrm{CpG}$ sites promotes the substantial suppression of transcriptional activities by directly or indirectly blocking the binding sites of certain transcription factors. The E6 and E7 genes, which are suppressed by HPV E2 gene products, 
Table III. AUC values obtained from ROC analyses of individual or combined CpG sites.

\begin{tabular}{llll}
\hline CpG site & AUC (95\% CI) & Sensitivity, $\%$ & Specificity, $\% \quad$ Threshold, $\%$
\end{tabular}

CC vs. normal tissue/LSIL and HSIL

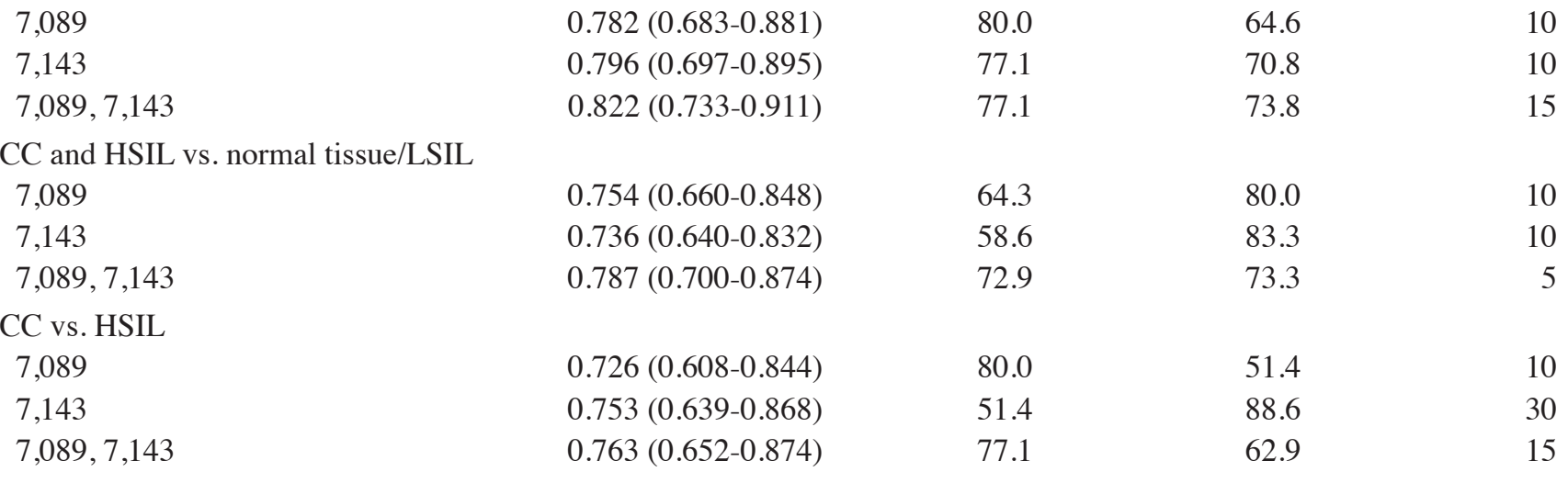

AUC, Area under curve; CI, confidence interval; ROC, receiver operating characteristic; CpG, cytosine-phosphate-guanine; LSIL, low-grade intraepithelial lesions; HSIL, high-grade intraepithelial lesions.

A

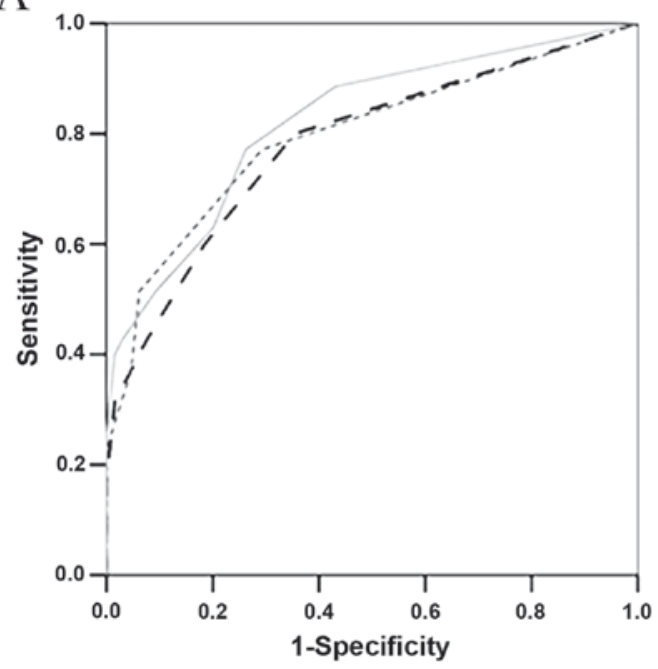

C

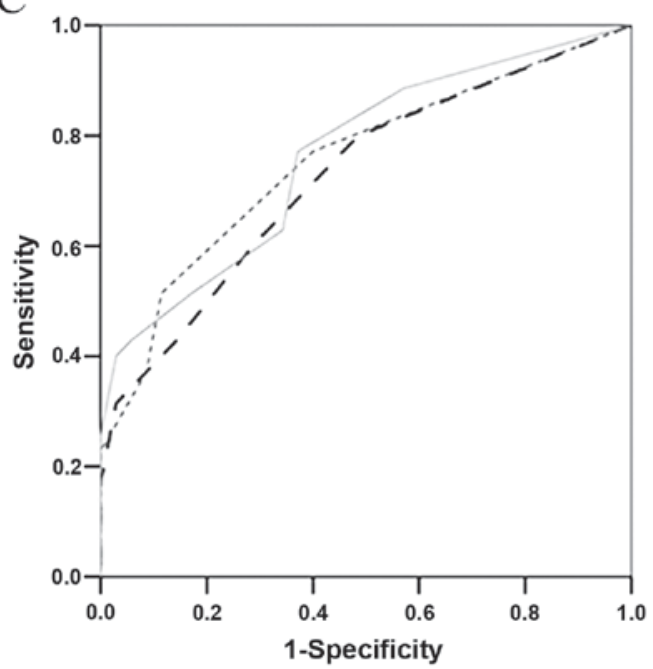

B

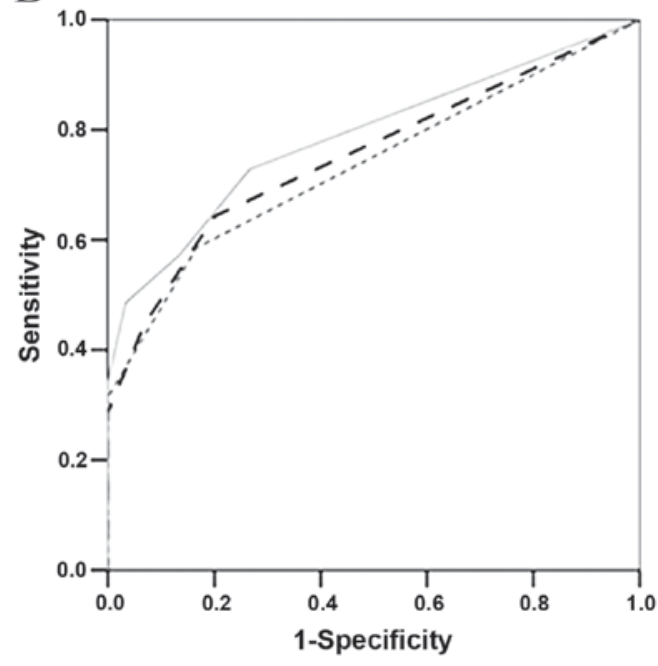

Figure 2. Receiver operating characteristic curves for the distinction between DNA samples using the DNA methylation frequency of CpG sites 7,089 and 7,143 individually or in combination. (A) CC vs. normal tissue/LSIL and HSIL. (B) CC and HSIL vs. normal tissue/LSIL. (C) CC vs. HSIL. CpG, cytosine-phosphate-guanine; CC, cervical cancer; LSIL, low-grade intraepithelial lesions; HSIL, high-grade intraepithelial lesions. 
are able to express oncogenic proteins that are necessary for transformation and malignant progression (34). During productive infection, E6 and E7 are expressed at relatively low levels due to the transcriptional suppression of E2 gene products (35). The methylation of E2 binding sites prevents the E2 protein from binding directly to DNA, leading to reduced regulation of E6 and E7 gene expression levels and the expression of oncoproteins (36). In the present study, the proportion of methylation was highest in cervical swab DNA samples from patients with $\mathrm{CC}$, and was lowest at $\mathrm{CpG}$ sites in the promoter region in DNA samples from patients with normal tissue/LSIL. The methylation proportions of DNA samples between patients with normal tissue/LSIL, HSIL and $\mathrm{CC}$ were significantly different. The methylation proportions of cervical swab DNA samples at the $5 \mathrm{CpG}$ sites (nt 31, 37, 43, 52 and 58) may aid evaluation of the incidence of cervical cancer. Among the DNA samples studied in the present study, an increased number of methylated $\mathrm{CpG}$ sites were identified in the HPV 16 promoter region, compared with the enhancer core, suggesting that the methylation of the HPV 16 promoter may be of increased importance, compared with that of the enhancer (21). CpG site 7,859, which is located in the origin of replication, exhibited no methylation in the DNA samples from patients with HSIL, hypomethylation in DNA samples from patients with LSIL (2.70\%) and hypermethylation in DNA samples from patients with CC $(24.32 \%)$. As a component of the HPV replication origin, the low methylation proportion at CpG site 7,859 in DNA samples from patients with LSIL and HSIL may increase viral replication and aid the establishment of infection (37).

Previous studies have reported that the proportion of methylation is higher in DNA specimens from patients without CIN2/3, and lower in those from patients with CIN2/3 at the 11 CpG sites within the LCR (19). A study examining the methylation patterns of $19 \mathrm{HPV} 16 \mathrm{CpG}$ site dinucleotides within the L1 gene and the long control region observed the frequency of methylation to be highest in CC and lowest in CINs (low and high grade) (37). In another study, the methylation status of 8 $\mathrm{CpG}$ sites in the HPV 16 promoter region and enhancer core were examined in clinical DNA samples using pyrosequencing, demonstrating that the proportion of methylated DNA samples was highest in $\mathrm{CC}$, followed by asymptomatic infection and CIN3, and was lowest in CIN1/2 (21). The discrepancy of the methylation status between these results may be due to the methods utilized for methylation evaluation and the classification of cervical disease grade and differences between ethnic groups. The present study observed that the proportion of methylation in DNA samples at HPV 16 3'-L1 and the LCR increased as cervical lesions progressed. The increased methylation proportion in CC samples appears paradoxical, as the DNA methylation mechanism generally leads to transcriptional suppression (21). However, certain HPV genomes exist in the episomal, unmethylated form in cancer cells, which maintains the transformation of viral genomes (38).

The present study revealed that $\mathrm{CpG}$ sites in the $\mathrm{L} 1$ gene provided effective distinction of DNA samples from patients with CC. Among them, $\mathrm{CpG} 7,134$ was able to distinguish between normal tissue/LSIL and CC, as well as HSIL and CC; however, was not appropriate for detecting normal tissue/LSIL vs. HSIL. ROC curves were constructed to assess the diagnostic utility of the methylated $\mathrm{CpG}$ sites 7,089 and 7,143 for various cervical lesions. The results demonstrated that the AUC values were improved using combinations of these two $\mathrm{CpG}$ sites, yielding $77.1 \%$ sensitivity and $73.8 \%$ specificity for the detection of CC with a critical threshold value of $15 \%$ methylation frequency. A similar study conducted by Bryant et al (11) demonstrated that the optimum separation between normal and dyskaryotic samples was achieved by assessment of the $\mathrm{CpG}$ sites nt 5,600 and 5,609 in the L1/L2 region, based on ROC curve analysis. Mirabello et al (39) quantified the methylation frequency of $\mathrm{CpG}$ sites in the HPV $16 \mathrm{~L} 1$ region (nt 6,367 and 6,389), revealing that the methylation level of $\mathrm{CpG} 6,367$ was a predictor of the development of CIN2 (AUC values>0.7), and that $\mathrm{CpG}$ 6,389 was able to identify various cervical lesions. All the aforementioned results demonstrate that the L1 gene may be the primary target of methylation by host defense mechanisms during the development of cervical lesions, and may be of potential use in identifying cervical disease.

In conclusion, an association between HPV 16 3'-L1/LCR methylation and $\mathrm{CC}$ development was observed in female patients from northeastern China. Of the $18 \mathrm{CpG}$ sites investigated, the most informative were at nt 7,089 and 7,143 within the L1 region. Cervical lesions in normal tissue/LSIL, HSIL or CC may be distinguished according to the methylation frequencies of these two $\mathrm{CpG}$ sites. The mean methylation frequency of the combination of $\mathrm{CpG}$ sites 7,089 and 7,143 was particularly effective for determining sensitivity and specificity. The methylation status of the $\mathrm{CpG}$ sites at nt 31, 37, 43, 52 and 58 was valuable for evaluating the incidence of CC. These data indicate that the quantification of HPV DNA methylation in the L1 gene and the promoter region may provide a candidate biomarker to aid the distinction between benign HPV infections and those that may progress to precancerous infections.

\section{Acknowledgements}

The present study was supported by the National Natural Science Foundation of China (grant nos. 81171580 and 81171581) and the Outstanding Scientific Fund of Shengjing Hospital (grant no. 201105).

\section{References}

1. Murakami I, Fujii T, Dan K, Saito M, Ohno A, Iwata T and Aoki D: Methylation of human papillomavirus- 52 and -58 is a candidate biomarker in cervical neoplasia. J Clin Virol 58: 149-154, 2013.

2. Marongiu L, Godi A, Parry JV and Beddows S: Human Papillomavirus 16, 18, 31 and 45 viral load, integration and methylation status stratified by cervical disease stage. BMC Cancer 14: 384, 2014.

3. Schiffman M, Castle PE, Jeronimo J, Rodriguez AC and Wacholder S: Human papillomavirus and cervical cancer. Lancet 370: 890-907, 2007.

4. Clarke MA, Wentzensen N, Mirabello L, Ghosh A, Wacholder S, Harari A, Lorincz A, Schiffman M and Burk RD: Human papillomavirus DNA methylation as a potential biomarker for cervical cancer. Cancer Epidemiol Biomarkers Prev 21: 2125-2137, 2012.

5. Kalantari M, Osann K, Calleja-Macias IE, Kim S, Yan B, Jordan S, Chase DM, Tewari KS and Bernard HU: Methylation of human papillomavirus 16, 18, 31, and $45 \mathrm{~L} 2$ and L1 genes and the cellular DAPK gene: Considerations for use as biomarkers of the progression of cervical neoplasia. Virology 448: 314-321, 2014. 
6. Whiteside MA, Siegel EM and Unger ER: Human papillomavirus and molecular considerations for cancer risk. Cancer 113 (10 Suppl): S2981-S2994, 2008.

7. Kim SS, Suh DS, Kim KH, Yoon MS and Choi KU: Clinicopathological significance of atypical glandular cells on Pap smear. Obstet Gynecol Sci 56: 76-83, 2013.

8. Zhou J, Tomashefski JF Jr, Sawady J, Ferrer H and Khiyami A: The diagnostic value of the ThinPrep pap test in endometrial carcinoma: A prospective study with histological follow-up. Diagn Cytopathol 41: 408-412, 2013.

9. De Strooper LM, vanZummeren M, Steenbergen RD,Bleeker MC, Hesselink AT, Wisman GB, Snijders PJ, Heideman DA and Meijer CJ: CADM1, MAL and miR124-2 methylation analysis in cervical scrapes to detect cervical and endometrial cancer. J Clin Pathol 67: 1067-1071, 2014.

10. Arbyn M, Ronco G, Anttila A, Meijer CJ, Poljak M, Ogilvie G, Koliopoulos G, Naucler P, Sankaranarayanan R and Peto J: Evidence regarding human papillomavirus testing in secondary prevention of cervical cancer. Vaccine 30 (Suppl 5): F88-F99, 2012.

11. Bryant D, Tristram A, Liloglou T, Hibbitts S, Fiander A and Powell N: Quantitative measurement of human papillomavirus type $16 \mathrm{~L} 1 / \mathrm{L} 2 \mathrm{DNA}$ methylation correlates with cervical disease grade. J Clin Virol 59: 24-29, 2014.

12. Baylin SB and Herman JG: DNA hypermethylation in tumorigenesis: Epigenetics joins genetics. Trends Genet 16: 168-174, 2000.

13. Shivapurkar N, Sherman ME, Stastny V, Echebiri C, Rader JS, Nayar R, Bonfiglio TA, Gazdar AF and Wang SS: Evaluation of candidate methylation markers to detect cervical neoplasia. Gynecol Oncol 107: 549-553, 2007.

14. Kalantari M, Villa LL, Calleja-Macias IE and Bernard HU: Human papillomavirus-16 and -18 in penile carcinomas: DNA methylation, chromosomal recombination and genomic variation. Int J Cancer 123: 1832-1840, 2008.

15. Wentzensen N, Sun C, Ghosh A, Kinney W, Mirabello L, Wacholder S, Shaber R, LaMere B, Clarke M, Lorincz AT, et al: Methylation of HPV18, HPV31, and HPV45 genomes and cervical intraepithelial neoplasia grade III. J Natl Cancer Inst 104: 1738-1749, 2012

16. Sun Z, Lu Z, Liu J, Wang G, Zhou W, Yang L, Liu C, Wang B and Ruan Q: Genetic variations of E6 and long control region of human papillomavirus type 16 from patients with cervical lesion in Liaoning, China. BMC Cancer 13: 459, 2013.

17. Verma I, Jain V and Kaur T: Application of bethesda system for cervical cytology in unhealthy cervix. J Clin Diagn Res 8: OC26-OC30, 2014.

18. Li LC and Dahiya R: MethPrimer: Designing primers for methylation PCRs. Bioinformatics 18: 1427-1431, 2002.

19. Xi LF, Jiang M, Shen Z, Hulbert A, Zhou XH, Lin YY, Kiviat NB and Koutsky LA: Inverse association between methylation of human papillomavirus type 16 DNA and risk of cervical intraepithelial neoplasia grades II or III. PLoS One 6: e23897, 2011.

20. Zhu WG, Srinivasan K, Dai Z, Duan W, Druhan LJ, Ding H, Yee L, Villalona-Calero MA, Plass C and Otterson GA: Methylation of adjacent $\mathrm{CpG}$ sites affects $\mathrm{Sp} 1 / \mathrm{Sp} 3$ binding and activity in the p21 (Cip1) promoter. Mol Cell Biol 23: 4056-4065, 2003.

21. Hong D, Ye F, Lu W, Hu Y, Wan X, Chen Y and Xie X: Methylation status of the long control region of HPV 16 in clinical cervical specimens. Mol Med Rep 1: 555-560, 2008

22. Bryant D, Onions T, Raybould R, Jones S, Tristram A, Hibbitts S, Fiander A and Powell N: Increased methylation of human papillomavirus type 16 DNA correlates with viral integration in Vulval Intraepithelial Neoplasia. J Clin Virol 61: 393-399, 2014.

23. Ding DC, Chiang MH, Lai HC, Hsiung CA, Hsieh CY and Chu TY: Methylation of the long control region of HPV16 is related to the severity of cervical neoplasia. Eur J Obstet Gynecol Reprod Biol 147: 215-220, 2009.
24. Doerfler W, Remus R, Müller K, Heller H, Hohlweg U and Schubbert R: The fate of foreign DNA in mammalian cells and organisms. Dev Biol (Basel) 106: 89-97; discussion 143-160, 2001.

25. Daniel B, Mukherjee G, Seshadri L, Vallikad E and Krishna S: Changes in the physical state and expression of human papillomavirus type 16 in the progression of cervical intraepithelial neoplasia lesions analysed by PCR. J Gen Virol 76: 2589-2593, 1995.

26. Daniel B, Rangarajan A, Mukherjee G, Vallikad E and Krishna S: The link between integration and expression of human papillomavirus type 16 genomes and cellular changes in the evolution of cervical intraepithelial neoplastic lesions. J Gen Virol 78: $1095-1101,1997$.

27. Schwarz E, Freese UK, Gissmann L, Mayer W, Roggenbuck B, Stremlau A and zur Hausen H: Structure and transcription of human papillomavirus sequences in cervical carcinoma cells. Nature 314: 111-114, 1985.

28. Vinokurova S, Wentzensen N, Kraus I, Klaes R, Driesch C, Melsheimer P, Kisseljov F, Dürst M, Schneider A and von Knebel Doeberitz M: Type-dependent integration frequency of human papillomavirus genomes in cervical lesions. Cancer Res 68: 307-313, 2008

29. Dutta S, Chakraborty C, Dutta AK, Mandal RK, Roychoudhury S, Basu P and Panda C: Physical and methylation status of human papillomavirus 16 in asymptomatic cervical infections changes with malignant transformation. J Clin Pathol 68: 206-211, 2015.

30. Qiu C, Zhi Y, Shen Y, Gong J, Li Y and Li X: High-resolution melting analysis of HPV-16L1 gene methylation: A promising method for prognosing cervical cancer. Clin Biochem 48: 855-859, 2015 .

31. Bird A: DNA methylation patterns and epigenetic memory. Genes Dev 16: 6-21, 2002.

32. Fuks F: DNA methylation and histone modifications: Teaming up to silence genes. Curr Opin Genet Dev 15: 490-495, 2005.

33. Mino A, Onoda N, Yashiro M, Aya M, Fujiwara I, Kubo N, Sawada T, Ohira M, Kato Y and Hirakawa K: Frequent p16 $\mathrm{CpG}$ island hypermethylation in primary remnant gastric cancer suggesting an independent carcinogenic pathway. Oncol Rep 15: 615-620, 2006.

34. Münger K, Baldwin A, Edwards KM, Hayakawa H, Nguyen CL, Owens M, Grace M and Huh K: Mechanisms of human papillomavirus-induced oncogenesis. J Virol 78: 11451-11460, 2004.

35. Yang HJ: Aberrant DNA methylation in cervical carcinogenesis. Chin J Cancer 32: 42-48, 2013.

36. Tan SH, Leong LE, Walker PA and Bernard HU: The human papillomavirus type 16 E2 transcription factor binds with low cooperativity to two flanking sites and represses the E6 promoter through displacement of Sp1 and TFIID. J Virol 68: 6411-6420, 1994.

37. Kalantari M, Calleja-Macias IE, Tewari D, Hagmar B, Lie K, Barrera-Saldana HA, Wiley DJ and Bernard HU: Conserved methylation patterns of human papillomavirus type 16 DNA in asymptomatic infection and cervical neoplasia. J Virol 78: 12762-12772, 2004.

38. Rajeevan MS, Swan DC, Nisenbaum R, Lee DR, Vernon SD, Ruffin MT, Horowitz IR, Flowers LC, Kmak D, Tadros T, et al: Epidemiologic and viral factors associated with cervical neoplasia in HPV-16-positive women. Int J Cancer 115: 114-120, 2005.

39. Mirabello L, Schiffman M, Ghosh A, Rodriguez AC, Vasiljevic N, Wentzensen N, Herrero R, Hildesheim A, Wacholder S, Scibior-Bentkowska D, et al: Elevated methylation of HPV16 DNA is associated with the development of high grade cervical intraepithelial neoplasia. Int J Cancer 132: 1412-1422, 2013. 